\title{
The change of hydrological variables and its effects on vegetation in Central Asia
}

\author{
Qing Peng ${ }^{1} \cdot$ Ranghui Wang ${ }^{1,2} \cdot$ Yelin Jiang ${ }^{1} \cdot$ Cheng $\mathrm{Li}^{3} \cdot$ Wenhui Guo $^{1}$
}

Received: 12 April 2021 / Accepted: 11 July 2021 / Published online: 31 August 2021

(c) The Author(s) 2021

\begin{abstract}
Water is an important factor that affects local ecological environments, especially in drylands. The hydrological cycle and vegetation dynamics in Central Asia (CA) have been severely affected by climate change. In this study, we employed data from Gravity Recovery and Climate Experiment (GRACE), Global Land Data Assimilation System (GLDAS), Global Land Evaporation Amsterdam Model, and Climate Research Unit to analyze the spatiotemporal changes in hydrological factors (terrestrial water storage (TWS), evapotranspiration, precipitation, and groundwater) in CA from 2003 to 2015. Additionally, the spatiotemporal changes in vegetation dynamics and the influence of hydrological variables on vegetation were analyzed. The results showed that the declining rates of precipitation, evapotranspiration, GRACE-TWS change, GLDAS-TWS change and GW change were $0.40 \mathrm{~mm} /$ year, $0.11 \mathrm{~mm} /$ year, $50.46 \mathrm{~mm} /$ year $(p<0.05), 8.38 \mathrm{~mm} /$ year, and $41.18 \mathrm{~mm} /$ year $(p<0.05)$, respectively. Human activity (e.g., groundwater pumping) was the dominant in determining the GW decline in CA. Precipitation dominated the changes in evapotranspiration, GRACE-TWS and GLDAS-TWS $(p<0.05)$. The 2- to 3-month lagging signal has to do with the transportation from the ground surface to groundwater. The change in the normalized difference vegetation index (NDVI) from 2003 to 2015 indicated the slight vegetation degradation in CA. The results highlighted that precipitation, terrestrial water storage, and soil moisture make important contributions to the vegetation dynamics changes in CA. The effect of precipitation on vegetation growth in spring was significant $(p<0.05)$, while the soil moisture effect on vegetation in summer and autumn was higher than that of precipitation.
\end{abstract}

Keywords Hydrological cycle $\cdot$ Terrestrial water storage $\cdot$ NDVI $\cdot$ Human activity $\cdot$ Central Asia

\section{Introduction}

In areas threatened by water storage, hydrological cycle is the dominating factor for sustaining terrestrial ecosystems, as its direct impact on vegetation dynamics (Lohse et al. 2009; Reyer et al. 2013; Ndehedehe et al. 2019). Anthropogenic climate change influences the hydrological cycle, providing greater stress on water-limited areas. Central Asia

Ranghui Wang

rhwang@nuist.edu.cn

1 School of Applied Meteorology, Nanjing University of Information Science and Technology, Nanjing, China

2 Key Laboratory of Agricultural Meteorology, Collaborative Innovation Center of Atmospheric Environment and Equipment Technology, Nanjing University of Information Science and Technology, Nanjing, China

3 School of Horticulture and Plant Protection, Yangzhou University, Yangzhou, China
(CA) has experienced increases in the frequency and magnitude of extreme temperatures and precipitation $(\mathrm{P})$, with a larger warming rate than global average (Hu et al. 2014). The continuous warming will lead to an increase in evapotranspiration (ET) and a decrease in glaciers (Zhang et al. 2014; Gao et al. 2018). The hydrologic cycle in CA has been intensified and accelerated, which has led to changes in the local water balance (Bernauer and Siegfried 2012; Deng and Chen 2017). These modifications of the water balance result in changes to terrestrial ecosystems, which ultimately cause a decrease in biodiversity and increases in salinization and desertification (D’Odorico et al. 2013; Feng et al. 2016).

Vegetation dynamics is able to reflect the interaction between hydrological and terrestrial ecosystems directly (Ravi et al. 2010; Shen et al. 2013). The normalized difference vegetation index (NDVI) has been widely used to monitor vegetation dynamics in recent researches (Andrew et al. 2017). The study of hydrological changes and their effects on vegetation is helpful not only for understanding 
the impact of climate change on the water cycle but also for evaluating the ecological environment. Terrestrial water storage (TWS) is an important part of the terrestrial water cycle, which is defined as the sum of groundwater (GW), surface water, soil moisture (SM), snow water equivalent (SWE), and vegetation canopy water (Syed et al. 2008). GW is an important water source for the survival and growth of natural vegetation in dryland. Although TWS includes SM and GW, the influence of each factor on vegetation dynamics is different. P and ET are also crucial factors and act as flux variables, moving water between reservoirs within the water cycle.

Many studies have examined the relationship between $\mathrm{P}$ and vegetation anomalies in CA (Jiang et al. 2017; Li et al. 2015b). Increased $P$ provides favorable conditions for vegetation growth in drylands ( $\mathrm{Li}$ et al. 2015b), and ET has positive correlations with NDVI in most areas, despite the fact that some areas with a low NDVI and high ET feature the negative correlation (Suzuki et al. 2007; Xu et al. 2018b). In addition, SM and vegetation are strongly related, and an increase in SM may result in vegetation increase (Liu et al. 2016; Zhang et al. 2016). However, these studies focused on the response of vegetation to water resource changes mainly through a single indicator, such as P, ET, or SM. Vegetation, P, ET, SM, TWS, and GW all play important roles in land-atmosphere interactions (Jiao et al. 2017; Shen et al. 2013), and the single indicator research may hamper the understanding of eco-hydrological interactions. Therefore, it is necessary to study the response of vegetation to multiple indicators.

The analysis of hydrological indicators, such as TWS, P, ET, and GW, is often limited due to the spatial limitations of traditional measurement methods. The advances in remote sensing technology and the advent of the Gravity Recovery and Climate Experiment (GRACE) and the Global Land Surface Data Assimilation System (GLDAS) offer the possible estimation for water resources research over large spatial extents. GRACE data have been proposed to provide direct observations of changes in TWS (TWSC) and have been widely used in hydrological and ecological studies (Bai et al. 2019; Panda and Wahr 2016; Syed et al. 2008). GLDAS takes satellite- and ground-based observations and uses land surface modeling and data assimilation techniques to obtain SM, ET, SWE, and other hydrological data. The performance of GLDAS data has been validated in the arid CA (Ghazanfari et al. 2013; Tan et al. 2018). Combining GRACE and GLDAS data can be used to estimate spatiotemporal changes in $\mathrm{GW}(\triangle \mathrm{GW})$, which is also an important part of water storage (Rodell et al. 2006; Long et al. 2016; Xu et al. 2018a). Combined with the analysis of P, ET, TWSC, $\triangle \mathrm{GW}$, and P minus ET (P-ET), changes to the water cycle can be well studied. Analyzing the status and trends of water resources in CA and the impact on vegetation dynamics may have implications on identification of water shortages in the future; thus, water resources can be proactively managed to reduce the losses and promote sustainable terrestrial ecosystems. In this study, multi-satellite observations and land surface model outputs were used to analyze the changes in water balance and vegetation dynamics in CA. We then quantified the spatiotemporal relationship between various hydrological variables and vegetation dynamics. Finally, we discussed the observed changes in the distribution of the components of the water cycle and the response of vegetation dynamics to these changes.

\section{Dataset descriptions and methods}

\subsection{Study area}

CA $\left(34.3^{\circ}-55.4^{\circ} \mathrm{N}, 46.5^{\circ}-96.4^{\circ} \mathrm{E}\right)$ consists of Kazakhstan (KAZ), Kyrgyzstan (KGZ), Uzbekistan (UZB), Tajikistan (TJK), Turkmenistan (TKM), and Xinjiang, China (CXJ) (Fig. 1) (Li et al. 2015a). Marked by semi-arid and desert regions, CA is a typical continental climate zone, with low P ( $227.02 \mathrm{~mm} /$ year average from 2003 to 2015) and high ET. The $P$ is mainly concentrated in mountainous areas, with very limited rainfall in basins and plains. During the dry seasons, the main water source in $\mathrm{CA}$ is seasonal melting water from large glaciers and permanent snow cover. Bare areas, grassland, and sparse vegetation are the main vegetation types in the area (Fig. 1).

\subsection{Data and processing}

The datasets used in this study are presented in Table 1 .

(1) P: Monthly P data were provided by the Climate Research Unite Time Series 4.01 (CRU TS4.01) and were resampled into the $0.5^{\circ} \times 0.5^{\circ}$ grid (Harris and Jones 2017).

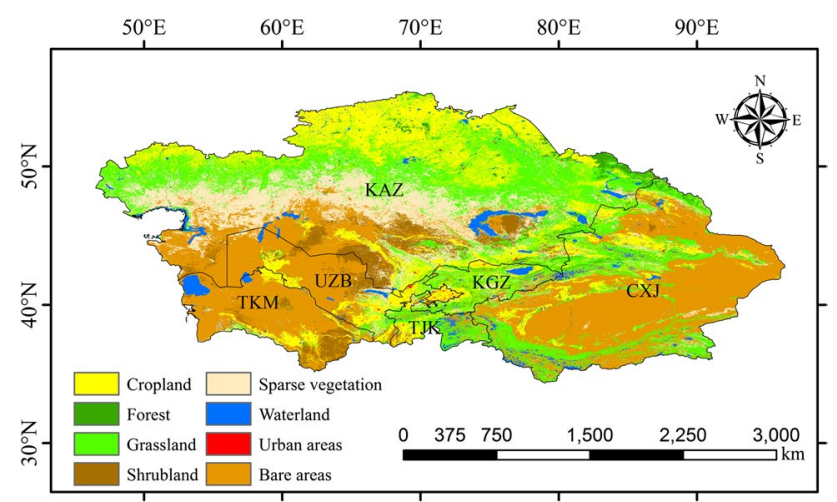

Fig. 1 Map of Central Asia denoting the locations of Kazakhstan (KAZ), Kyrgyzstan (KGZ), Uzbekistan (UZB), Tajikistan (TJK), Turkmenistan (TKM), and Xinjiang, China (CXJ) 
Table 1 Data source

\begin{tabular}{llll}
\hline Datasets & Spatial resolution & Temporal resolution & Source \\
\hline P & $0.5^{\circ} \times 0.5^{\circ}$ & Monthly & http://www.cru.uea.ac.uk/cru/data/hrg/ \\
ET & $0.25^{\circ} \times 0.25^{\circ}$ & Monthly & https://www.gleam.eu/?tdsourcetag=s_pcqq_aiomsg \\
GLDAS-TWSC & $0.25^{\circ} \times 0.25^{\circ}$ & Monthly & https://ldas.gsfc.nasa.gov/gldas/model-output \\
GRACE-TWSC & $0.5^{\circ} \times 0.5^{\circ}$ & Monthly & $\mathrm{http} / /$ www2.csr.utexas.edu/grace/ \\
Snow Cover & $0.05^{\circ} \times 0.05^{\circ}$ & Monthly & $\mathrm{https://modis.gsfc.nasa.gov/}$ \\
NDVI & $1 \mathrm{~km} \times 1 \mathrm{~km}$ & Monthly & $\mathrm{https://modis.gsfc.nasa.gov/}$ \\
\hline
\end{tabular}

(2) ET: The monthly ET data were obtained from the Global Land Evaporation Amsterdam Model (GLEAM) version 3.3a (Brecht et al. 2016). This model based on the Priestley-Taylor equation estimates the different components of terrestrial evaporation from satellite data. It has reasonable accuracy for current eddy covariance observations and has been widely used in large-scale ecological, hydrological, and climatic studies (Brecht et al. 2016; Martens et al. 2017).

(3) TWS: The monthly TWSC was derived from the GRACE CSR-Mascons product (Save et al. 2016). This study used monthly GRACE data from 2003 to 2015 with a spatial resolution of $0.5^{\circ} \times 0.5^{\circ}$. Missing values were filled through linear interpolation.

The changes in SM (2im depth), SWE, and canopy water $(\mathrm{CW})$ were obtained by GLDAS using the Noah land surface model (Rodell et al. 2004). And then, these data were used to calculate the TWSC through Eq. (1). The GLDAS data were resampled at the $0.25^{\circ} \times 0.25^{\circ}$ spatial resolution.

$\mathrm{TWSC}_{\mathrm{GLDAS}}=\triangle \mathrm{SM}+\triangle \mathrm{SWE}+\triangle \mathrm{CW}$

(4) P-ET: As a cumulative effect of the water flux (P-ETrunoff) over time, it is relative with TWS, (Wang et al. 2017). Since rivers in CA are mainly inland rivers (Deng and Chen 2017), we focus on the relationship between P-ET and TWSC. We resampled the ET data with the $0.5^{\circ} \times 0.5^{\circ}$ resolution and then derived the P-ET value.

(5) Snow cover: Snow cover data were obtained from the MODIS monthly snow cover product (MOD10C1). Snow cover changes in the Tianshan area of Xinjiang were obtained over the study period by calculating the difference between the annual maximum and minimum snow cover.

(6) The NDVI obtained from the MODIS vegetation index monthly product (MOD13A3) during 2003-2015 was used to study the dynamic changes in vegetation.

\subsection{Estimate of GW change}

The month-to-month changes in both GRACE-derived (GRACE-TWSC) and GLDAS-derived TWS (GLDASTWSC) accounted for the same variables (SM, CW, SWE). However, GRACE-TWSC accounts for an additional variable, GW, which is absent from GLDAS-TWSC. Therefore, the $\triangle \mathrm{GW}$ can be obtained by subtracting GLDAS-TWSC from GRACE-TWSC (Rodell et al. 2006; Long et al. 2016). The formula for $\triangle \mathrm{GW}$ calculation is listed as follows:

$\triangle \mathrm{GW}=\mathrm{TWSC}_{\mathrm{GRACE}}-\mathrm{TWSC}_{\mathrm{GLDAS}}$

\subsection{Trend and statistical analysis}

To analyze the temporal trends of the hydrological variables and NDVI in CA, we performed trend analysis using the following formula:

$\theta_{\text {slope }}=\frac{n \times \sum_{i=1}^{n} i \times C_{i}-\left(\sum_{i=2}^{n} i\right)\left(\sum_{i=1}^{n} C_{i}\right)}{n \times \sum_{i=1}^{n} i^{2}-\left(\sum_{i=1}^{n} i\right)^{2}}$

where $\theta_{\text {slope }}$ represents the overall trend of the variable in question, $n$ is the duration over which the trend analysis is performed, and $C_{i}$ is the specific hydrological variable or NDVI value for the year in question. We analyzed the annual and seasonal variations for all variables used in this study.

The Pearson correlation coefficient was used to identify the strength of the relationship between NDVI and each hydrological variable in this study using the following formula:

$r=\frac{\sum_{i=1}^{n}\left[\left(x_{i}-\bar{x}\right)\left(y_{i}-\bar{y}\right)\right]}{\sqrt{\sum_{i=1}^{n}\left(x_{i}-\bar{x}\right) \sum_{i=1}^{n}\left(y_{i}-\bar{y}\right)}}$

where $x_{i}$ represents the value of hydrological variables at time $i, y_{i}$ is the NDVI value at time $i, x$ is the average value of the hydrological variables, and $y$ is the average NDVI value. The probability value of each relationship was 
analyzed to determine whether the correlation was statistically significant.

\section{Results}

\subsection{The distribution of monthly average hydrological variables}

To analyze the monthly average contribution of each hydrologic variable in CA from 2003 to 2015, we quantified the monthly average values of P, ET, and TWSC for both GRACE and GLDAS, as well as $\triangle \mathrm{GW}$ (Fig. 2). The monthly average $P$ was relatively evenly distributed, with the driest month (September, $10 \mathrm{~mm}$ ) and the wettest month (May, $25 \mathrm{~mm}$ ) (Fig. 2a). ET values featured a clear seasonal variability, with the largest ET values in late spring and early summer and the lowest ET values in late autumn and early winter (Fig. 2b). The GRACE-TWSC and GLDASTWSC monthly averages showed seasonal variability as well, with increased TWSC being observed from late winter
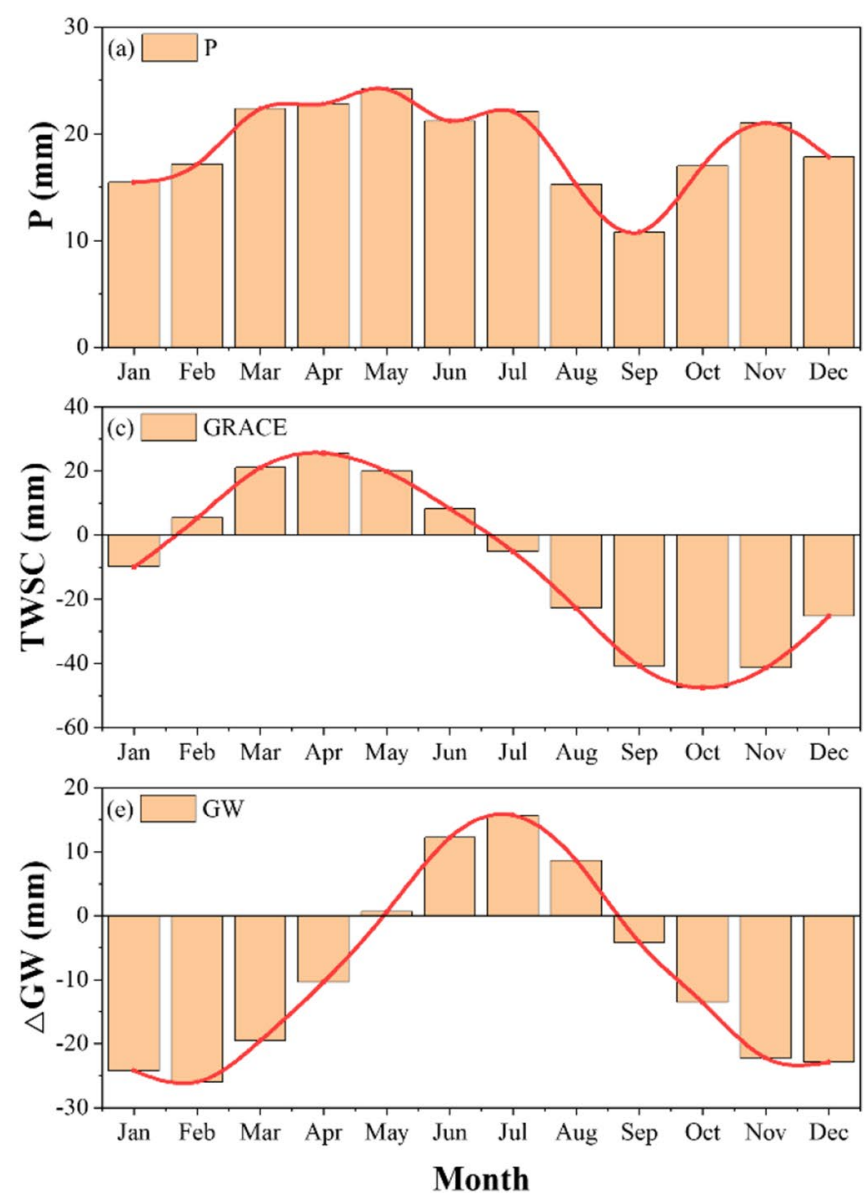

to early summer and decreased TWSC occurring from later summer to winter (Fig. 2c, d). The monthly mean $\triangle G W$ for the study period was quantified using Eq. (2). GW was losing from autumn to spring but gaining over the summer months (Fig. 2e). The seasonality was also shown in P-ET, with $\mathrm{P}$ gaining more water than evaporative losing in the autumn, winter, and early spring months and ET depleting more water than incoming rainfall in the late spring and summer months (Fig. 2f). The water storage in CA featured in the form of SM and GW.

\subsection{Spatiotemporal variation in hydrological variables}

The interannual variations in P, ET, GRACE-TWSC, GLDAS-TWSC, $\triangle \mathrm{GW}$, and P-ET in CA from 2003 to 2015 are shown in Fig. 3. The interannual changes in P, ET, GLDAS-TWSC, and P-ET each exhibited statistically insignificant trends, indicating that interannual changes to these variables decreased/increased in a predictable way (Fig. 3a, b, d, f). However, GRACE-TWSC decreased significantly
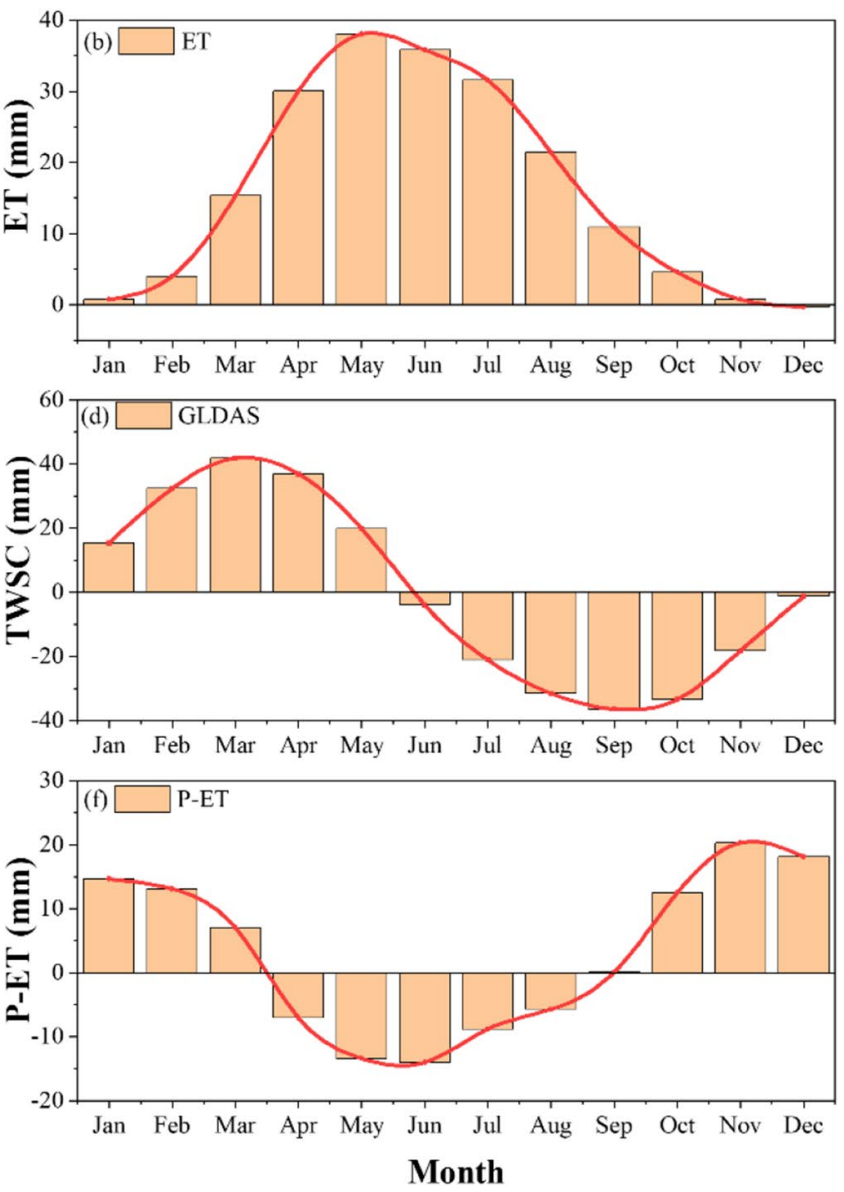

Fig. 2 Average monthly values of hydrological variables for the duration of the study with a P, b ET, $\mathbf{c}$ GRACE-TWSC, d GLDAS-TWSC, e $\triangle \mathrm{GW}$, and $\mathbf{f} \mathrm{P}$-ET 
Fig. 3 Interannual variation of hydrological variables with a P, b ET, c GRACE-TWSC, d GLDAS-TWSC, e $\triangle \mathrm{GW}$, and f P-ET

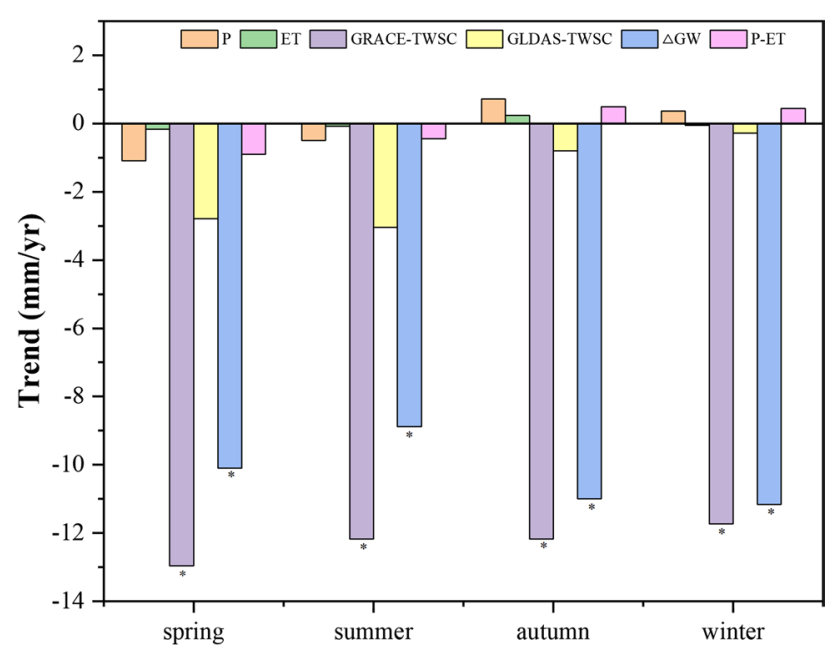

Fig. 4 Seasonal trends of hydrological variables analyzed in this study (*95\% confidence level)

from 2003 to 2015 , at a rate of $50.46 \mathrm{~mm} /$ year $(p<0.05)$ (Fig. 3c). As GRACE-TWSC contains GW as an internal variable, the interannual $\triangle \mathrm{GW}$ showed significant declines, with a rate of $41.18 \mathrm{~mm} / \mathrm{year}(p<0.05)$ (Fig. 3e). P increased after 2008 (Fig. 3a), GLDAS-TWSC displayed a similar change (Fig. 3c), and GRACE-TWSC declining trend was slowing (Fig. 3d) in the same period, which may be due to $P$ had a direct impact water storage. P, ET, GLDAS-TWSC, and P-ET seasonal variation were not reached a significant level (Fig. 4). However, GRACE-TWSC and $\triangle G W$ both showed negative trends across all seasons and remained statistically significant $(p<0.05)$. The trend of GLDAS-TWSC and $\triangle \mathrm{GW}$ variation showed counteractively pattern in four seasons (Fig. 4, yellow and blue bars), which can indicate that the process of water migration was from soil water content to GW.

The annual $\mathrm{P}$ in southwestern CA showed a downward trend, while the northeast showed an upward trend (Fig. 5a). The annual P decreased slightly in most parts of CA, especially in the Kunlun Mountains and Pamirs. The spatial distribution of ET showed a downward trend in the Amu Darya River basin and the area around the Caspian Sea, and it increased in the northeastern KAZ and most areas of CXJ. Around the Caspian Sea, there was a significant decrease in ET $(p<0.05)$. Across the study area, the GRACE-TWSC decreases significantly $(p<0.05)$, with the exception in northeastern KAZ and southern CXJ that showed the increasing trend in the GRACE-TWSC. The GLDAS-TWSC in most parts of the five Central Asian countries showed a downward trend, while most of CXJ showed an upward trend. $\triangle \mathrm{GW}$ exhibited a general declining trend over $\mathrm{CA}$, with most areas in CXJ showing a significant decreasing trend $(p<0.05)$. The P-ET presented a decreasing trend in most areas of CXJ and the Kunlun Mountains and an increasing trend in most areas of KAZ.

\subsection{Spatiotemporal variations in NDVI}

Using the annual variation and cumulative trend of NDVI during the growing season, we observed that NDVI show no statistically significant change throughout the study period (Fig. 6a). There were two distinct periods: a general increase in the accumulation of NDVI from 2003 to 2007 
followed by a large decrease in the accumulation of NDVI from 2007 to 2012, with some oscillations from 2012 to 2015 (Fig. 6b). When comparing the accumulation curve of NDVI to the general trends of GRACE-TWSC, GLDASTWSC, and $\triangle \mathrm{GW}$, it was seen that they followed the same general trend, indicating an interconnection between some hydrological variables and NDVI. Spatially, the distribution of NDVI in CA was heterogeneous. For large portions of CA, NDVI values were less than 0.2 (Fig. 7, red colors), identified as desert landscapes, which occupied
Fig. 5 Spatial distribution of annual hydrological variables with a P, b ET, c GRACETWSC, d GLDAS-TWSC, e $\triangle \mathrm{GW}$, and $\mathbf{f} \mathrm{P}-\mathrm{ET}$. (The region with plus symbol exhibits a linear trend that is statistically significant at $p<0.05$ )
Fig. 6 Interannual variations of spatially averaged NDVI (a) and cumulative curve of NDVI (b) in Central Asia from 2003 to 2015

Fig. 7 Spatial distribution of a NDVI and $\mathbf{b}$ NDVI trends from 2003 to 2015 in Central Asia
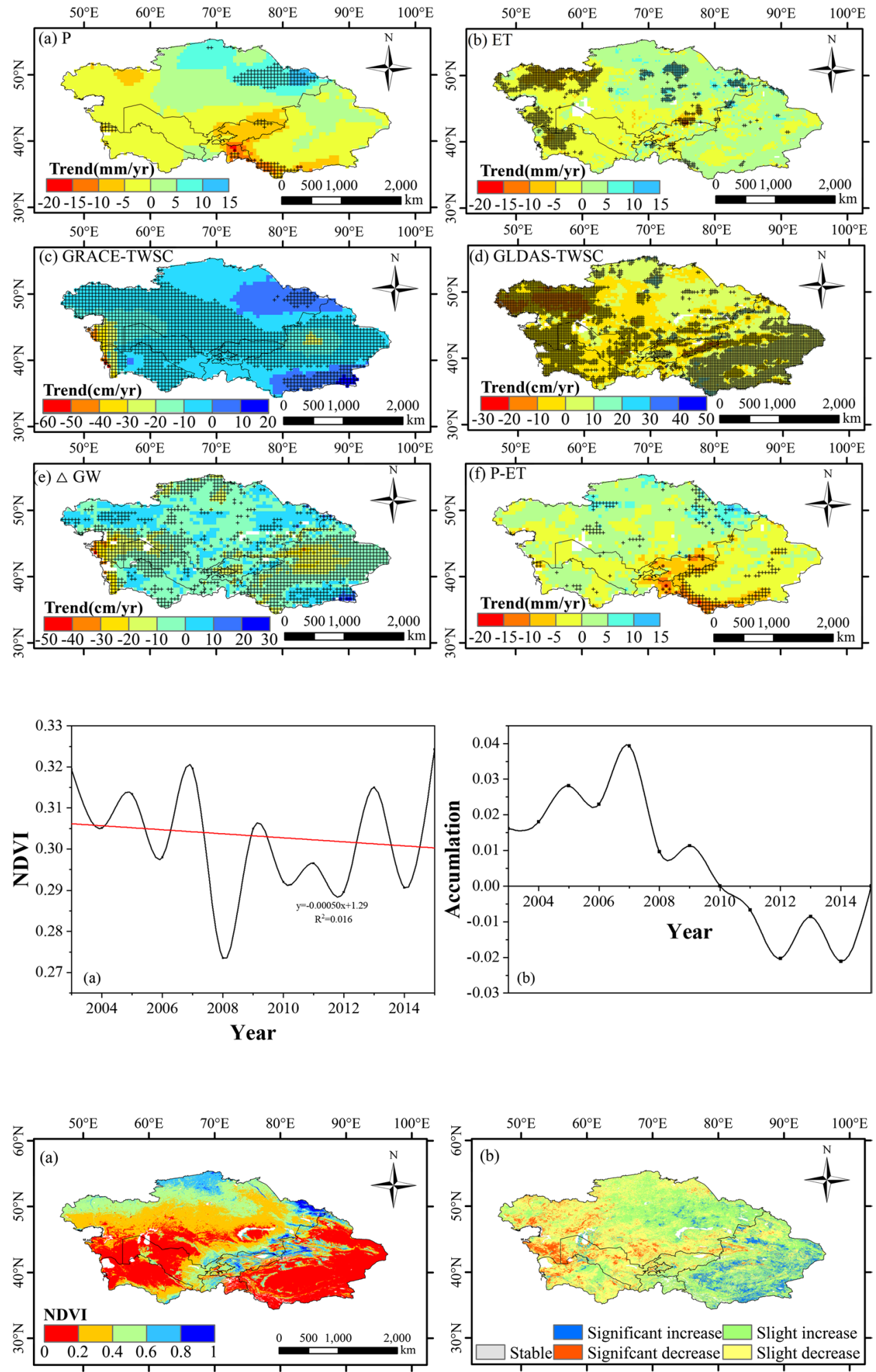
Table 2 Relationship between NDVI of growing season and hydrological variables in different periods (*95\% confidence level)

\begin{tabular}{lclllc}
\hline & Spring & Summer & Autumn & Winter & Annual \\
\hline P & $0.77^{*}$ & 0.51 & -0.03 & 0.29 & $0.77^{*}$ \\
ET & $0.80^{*}$ & $0.75^{*}$ & 0.27 & 0.29 & $0.87^{*}$ \\
GRACE-TWSC & 0.22 & 0.46 & 0.41 & 0.52 & 0.35 \\
GLDAS-TWSC & 0.53 & $0.70^{*}$ & $0.61^{*}$ & 0.36 & $0.62^{*}$ \\
GW change & -0.27 & 0.01 & 0.16 & 0.30 & -0.08 \\
P-ET & $0.65^{*}$ & 0.03 & -0.08 & 0.26 & 0.53 \\
\hline
\end{tabular}

approximately $39.35 \%$ of CA (Fig. 1). These regions include the Tarim Basin, Junggar Basin, and Kyzylkum Desert and areas around the Caspian Sea. NDVI values in the range of 0.2 to 0.4 accounted for $30.21 \%$ of the area, NDVI values in the range of 0.4 to 0.6 accounted for $21.29 \%$ of the total area, and NDVI values in the range of 0.6 to 1 accounted for only $9.14 \%$ of the area. The spatiotemporal trend of NDVI showed that approximately $51.68 \%$ of CA was decreased over the study time period, whereas $48.32 \%$ showed an increasing trend. The decline in NDVI corresponded to the degradation of vegetation and could be observed with significant decreases observed across CA.

\subsection{Impact of hydrological variables on the NDVI}

Vegetation in dryland is more sensitive to hydrological and climatic change. To explore the impact of hydrological variables on vegetation, we analyzed the correlation between NDVI and the different hydrological variables considered in this study (Table 2). The correlation between NDVI and P was statistically significant for the spring and annual periods $(p<0.05)$. Spring and summer are important periods for local vegetation growth, so the correlation between $\mathrm{P}$ and NDVI during this period was stronger than that in autumn and winter. ET also displayed a strong correlation for the spring and summer periods as well as for the annual period $(p<0.05)$. NDVI had a positive correlation with GRACETWSC in all periods, but the correlation did not reach the significance level. There was a significant positive correlation between NDVI and GLDAS-TWSC in summer, autumn, and throughout the year, indicating that the vegetation in summer and autumn relies strongly on SM. P-ET and NDVI had a significant positive correlation in the spring $(p<0.05)$ due to the increase in available water from $\mathrm{P}$ in the spring that can be used for plant growth.

Spatial correlation coefficients for hydrological variables and NDVI spanned a wide range covering positive and negative correlations. In general, correlations between NDVI and P, ET, GRACE-TWSC, and GLDAS-TWSC were statistically significant for positive values that covered areas of $20.89 \%, 30.49 \%, 19.79 \%$, and $22.11 \%$ of CA, respectively (Fig. 8a, b, c, d). These areas were mostly centered in KAZ and northern CXJ. Areas with significant negative correlation values were concentrated in bare land and sparse vegetation areas. More than half of the regions showed negative correlation between NDVI and $\Delta \mathrm{GW}$ and P-ET (Fig. 8e,
Fig. 8 The spatial distribution of the relationship between NDVI and hydrological variables: a NDVI and P, b NDVI and ET, $\mathbf{c}$ NDVI and GRACETWSC, $\mathbf{d}$ NDVI and GLDASTWSC, e NDVI and $\triangle G W$, and f NDVI and P-ET. (The region with plus symbol exhibits a linear trend that is statistically significant at $p<0.05$ )
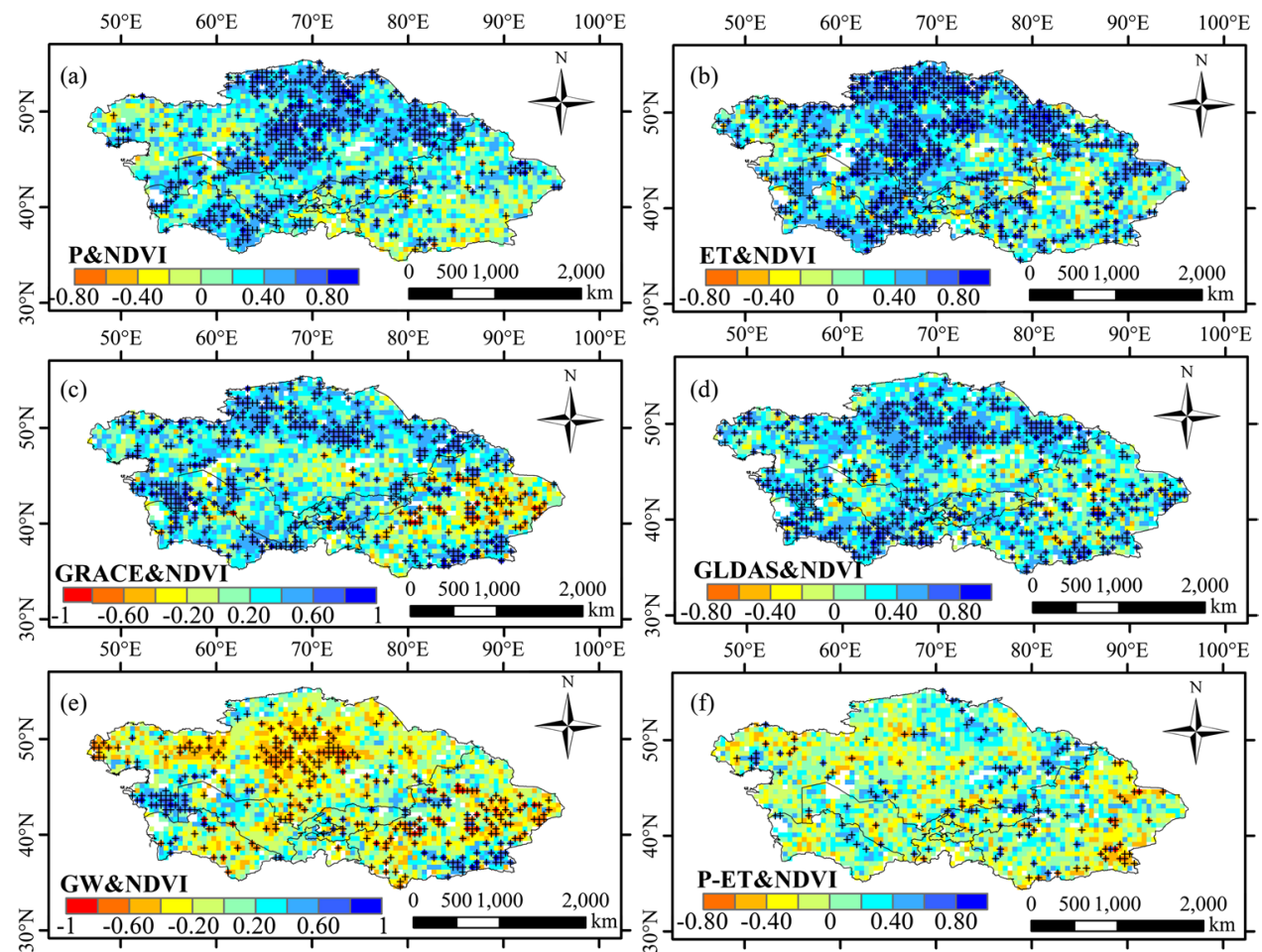
f). The negative correlation between NDVI and $\triangle \mathrm{GW}$ was mainly concentrated in KAZ and CXJ, with the negative correlation between NDVI and P-ET being focused on the eastern portion of CXJ. However, the area of negative correlation between NDVI and P-ET was less than that of NDVI and $\triangle \mathrm{GW}$.

\section{Discussion}

\subsection{Interactions among hydrological variables}

$\mathrm{P}$ is a key component within the water cycle and a crucial factor that could affect land-atmosphere interaction (Deng and Chen 2017; Chen et al. 2018). P was significantly positively correlated with ET, GRACE-TWSC, and GLDASTWSC $(p<0.05)$ due to its contribution to the water availability in soil and TWS (Fig. 9). ET had a significant positive correlation between P, GRACE-TWSC, and $\triangle \mathrm{GW}$ and a significant negative correlation with P-ET. The main reason is that ET contributed to the removal of water from the system, which impacted the vegetation dynamics and the TWS (Ndehedehe et al. 2019). The significant positive correlation between $\mathrm{P}$ and ET showed in our study. ET regime is shifted from energy-limited to water-limited, which is closely related to continuing water pumping (Gerten et al. 2004). In arid regions, ET is sensitive to water throughout the year (Yang et al. 2011). GRACE-TWSC had significant positive correlations with P, ET, GLDAS-TWSC, and $\triangle \mathrm{GW}$ $(p<0.05)$ and a significant negative correlation with P-ET $(p<0.05)$. This result was due to GRACE-TWSC being a bulk term that incorporates all the other variables. GLDASTWSC had a significant positive correlation with $\mathrm{P}$ and GRACE-TWSC $(p<0.05)$ and a significant negative correlation with $\Delta \mathrm{GW}(p<0.05)$. P and GLDAS-TWSC showed a significant positive correlation because the changes in SM were largely driven by changes in P (Meng et al. 2020; Qin et al. 2015). As GLDAS-TWSC measures the same hydrological parameters except for GW and is also a bulk parameter, the correlation between GLDAS-TWSC, and GRACE-TWSC is intuitive. $\triangle \mathrm{GW}$ had a significant positive correlation with ET and GRACE-TWSC $(p<0.05)$ and a significant negative correlation with GLDAS-TWSC and P-ET. This result was due to ET removing water from the system (Thomas 2008), GRACE-TWSC measuring GW, and GLDAS-TWSC not measuring GW, in addition to P-ET being an indicator of whether a plant will need water from another source that is not P. When there is a shortage of SM, GW moves upwards to replenish SM. Li et al. (2017) indicated that there is a perennial shortage of soil water in $\mathrm{CA}$, which can partly explain the reason why $\triangle \mathrm{GW}$ and SM changes feature a negative correlation.

Water storage in CA directly depends on P; however, $\mathrm{P}$ has no immediate effect on hydrological variables (Song et al. 2017; Thomas et al. 2014). The lag correlation coefficients of different time scales between $\mathrm{P}$ and
Fig. 9 Correlation diagram among hydrological variables (*95\% confidence level)

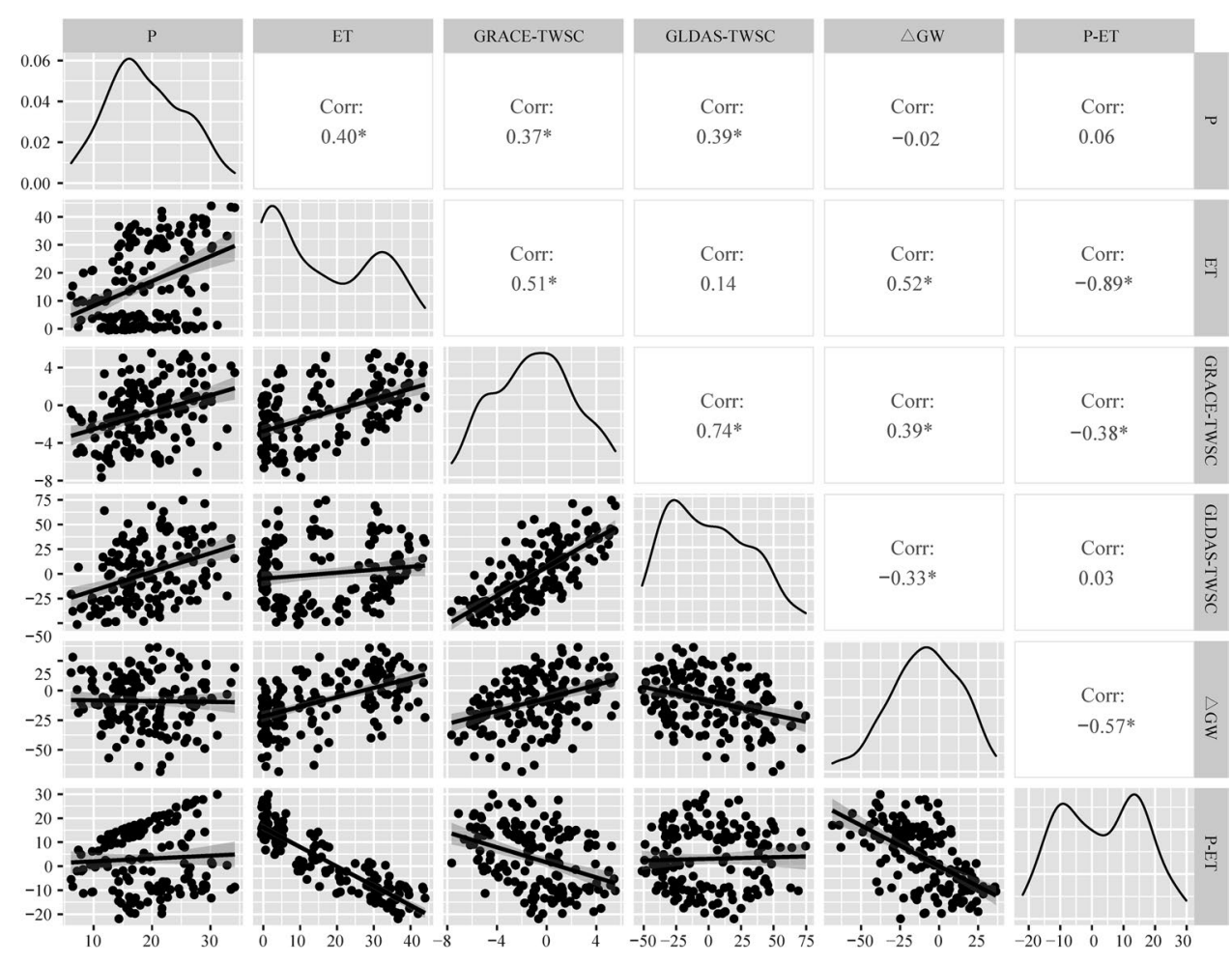




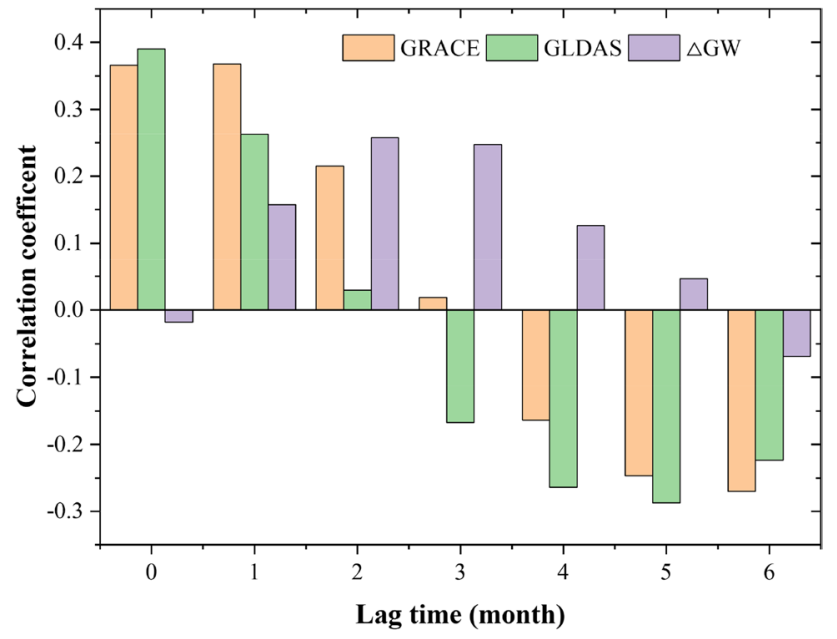

Fig. 10 The lag time correlation coefficients for $\mathrm{P}$ with hydrological variables GRACE-TWSC, GLDAS-TWSC, and $\triangle \mathrm{GW}$

GRACE-TWSC, GLDAS-TWSC, and $\triangle \mathrm{GW}$ in CA show that there is an impact between when a $P$ event occurs and when it is observed in the other variables (Fig. 10). GRACETWSC was moderately positively correlated with $\mathrm{P}$ at lag times of one month. This result was because it takes some time for $\mathrm{P}$ to infiltrate, increasing SM and eventually reaching GW as recharge. GRACE-TWSC and GLDAS-TWSC were weakly negatively correlated with $\mathrm{P}$ when the lag times were between 4 and 6 months. The lag effect of $P$ on GRACE-TWSC was more obvious than that on GLDASTWSC. Under non-lag conditions, P showed no correlation with the change in $\triangle G W$. A 2-month lag showed the highest positive correlation between $\mathrm{P}$ and $\triangle \mathrm{GW}$, indicating that it takes approximately 2 to 3 months for P to reach the GW.

\subsection{The main reason for groundwater change}

Figure 3 shows that P-ET cannot accurately represent TWSC because TWS is affected not only by climatic factors but also by human activities (Xie et al. 2018). Some recent studies also indicate that a modification in the atmospheric circulation and long-term evolution of $\mathrm{P}$ and ET within a given region may not be balanced; dry regions will become drier and wet regions will become wetter in the warming world (Held and Soden 2000; Chou et al. 2009; Greve et al. 2014). GW is one of the important parts of TWS. The annual water balance neglecting the runoff term can be described as follows:

$P_{i}-\mathrm{ET}_{i}=$ GRACE$\_T W S_{\operatorname{Dec}(i)}-$ GRACE_TWS $\mathrm{Jan}(i)$

where $P_{i}, \mathrm{ET}_{i}, \mathrm{GRACE}_{-} \mathrm{TWS}_{\mathrm{Dec}(i)}$, and GRACE_TW $\mathrm{Jan}(i)$ represent the annual values of $\mathrm{P}, \mathrm{ET}$, and December and
January GRACE-TWS at time $i$. We could yield the following equations if we sum the above equations:

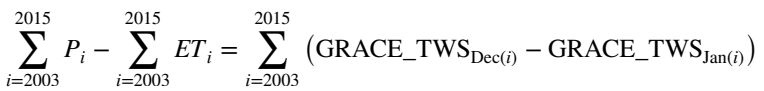

The sum of GRACE_TWS $\mathrm{Dec}(i)_{\text {minus GRACE_TW }}$ Jan $(i)$ from 2003 to 2015 roughly represents the TWS declining trend. The calculation showed that the average of the sum of annual P minus the sum of annual ET in CA from 2003 to 2015 was $477.41 \mathrm{~mm}$, while the average change in TWS from 2003 to 2015 was $-199.78 \mathrm{~mm}$. The magnitude of P-ET was less than the decrease in TWS. Moreover, Deng and Chen (2017) showed that in 2013, GW withdrawal in the Kaidu-Kongqa River basin and Aksu River basin was 3.3 times and 2.2 times that in 2007, respectively. GW withdrawal in the Yarkant River basin increased by $77 \%$ compared with 2007. Therefore, the excessive exploitation (human behaviors) of GW is the main cause of the decrease in GW storage.

In the context of climate change, the loss of glaciers and snow cover will further increase the uncertainties of the hydrological processes. Overall, hydrological processes have become more complex, and water resource systems have become increasingly fragile (Chen et al. 2018). It has been estimated that the total area and mass of glaciers in the Tianshan area from 1961 to 2012 decreased by $18 \pm 6 \%$ and $27 \pm 15 \%$, respectively (Farinotti et al. 2015). Approximately $97.52 \%$ of the glaciers in the Tianshan area showed receded trend, while only $2.14 \%$ of the glaciers advanced, and $0.34 \%$ of the glaciers did not change significantly (Chen et al. 2016). The maximum and minimum snow cover in the Tianshan area showed a slight decreasing trend from 2003 to 2015 (Figure S1). Increases in temperature reduced the snowfall/rainfall ratio in the mountains and exacerbated glacier melting, leading to the continued shrinkage of glaciers and snow cover (Berghuijs et al. 2014). The changes in glaciers and snow cover may be related to TWSC. It was found that melting glaciers and reduced snow cover were insufficient to account for all TWS losses. In addition, human activity (e.g., GW pumping) has now become a major factor in the decline of TWS in the Aral Sea region and northern Tarim River basin (Yang et al. 2015).

\subsection{The relationship between the NDVI and hydrological variables}

The maintenance and growth of vegetation in CA mainly depends on soil water and shallow groundwater from $P$ and surface runoff from mountain glaciers/snowmelt (Li et al. 2015b). Therefore, P, GRACE-TWSC, GLDAS-TWSC, and NDVI are expected to be highly positively correlated (Table 2). Studies have shown that 
the seasonality of $\mathrm{P}$ dominates changes in the structure and function of ecosystems in arid regions (Curreli et al. 2013; Jiao et al. 2017). This result is consistent with the results of our research in that there were differences in the correlation between the P and NDVI in different seasons in CA. There was a significant positive correlation between spring P and NDVI $(p<0.05)$ because vegetation consumes less water in the early growth period, and $\mathrm{P}$ can basically meet the needs of vegetation growth. Figure 2 shows that although there is more $\mathrm{P}$ in summer, ET is higher than P. Therefore, summer $P$ cannot maintain vegetation growth, and vegetation needs more SM for normal growth. Therefore, the positive correlation between summer $\mathrm{P}$ and the NDVI did not reach a significant level, while SM had a significant positive correlation with the NDVI $(p<0.05)$. $\mathrm{P}$ can only be absorbed and utilized by plants after it is stored in the soil (Qi et al. 2019). In addition, studies (de Beurs et al. 2015; Jiang et al. 2017) have shown that the $\mathrm{P}$ in spring and summer has a relatively strong impact on rain-fed vegetation. The positive correlation between spring and summer P and the NDVI is stronger than the correlation between autumn and winter $\mathrm{P}$ and NDVI. Therefore, the NDVI had a significant positive correlation with autumn GLDAS-TWSC $(p<0.05)$ but had a weak correlation with $\mathrm{P}$. There was a positive correlation between the NDVI and P in winter because winter snow is an important water resource for vegetation growth in the growing season. Snow cover reduces the damage to vegetation by winter monsoons and extreme temperatures, increases soil temperature in winter and spring runoff, and then has a positive effect on vegetation growth, especially sparse vegetation (Wahren et al. 2005). Forest soil is able to maintain higher water availability over longer periods, while the soil of sparse vegetation and shrubs water holding capacity is lower (Jiang et al. 2017). Therefore, vegetation in CA is immediately affected by available water, so annual $\mathrm{P}$ has a significant impact on vegetation $(p<0.05)$. Vegetation transpiration is an important part of ET, so there was a positive correlation between the ET and NDVI. In addition, spring and summer have the best vegetation conditions, so the correlation between the ET and NDVI was significant $(p<0.05)$. According to our results, GRACETWSC and GLDAS-TWSC have important contributions to vegetation. However, since $\triangle G W$ is a product of subtracting GLDAS-TWSC from GRACE-TWSC, it should indicate that GW plays a larger role in vegetation growth. However, the research results do not reflect this. This result is most likely because the $\triangle \mathrm{GW}$ in CA is mainly caused by human activities rather than by climate changes. Additionally, GW is used for agricultural irrigation to affect vegetation by changing SM rather than directly reflecting the impact of GW on vegetation.

\section{Conclusions}

Based on multi-satellite data and land model outputs for the period from 2003 to 2015, we analyzed the roles of seasonal and interannual trends on changes in water balance in CA and the impact on vegetation dynamics. The main conclusions were as follows:

(1) There were seasonal differences in the variation in hydrological factors across CA. ET was highest in summer and lowest in autumn. GRACE-TWSC and GLDAS-TWSC exhibited similar trends, with increases in spring and summer and decreases in autumn and winter. P-ET and $\Delta \mathrm{GW}$ exhibited the opposite trend. $\triangle \mathrm{GW}$ showed a positive change in summer and a negative change in autumn and winter, whereas P-ET displayed the opposite trend. In the spring and summer, TWS increased due to increases in GW and SM. From 2003 to 2015, GRACE-TWSC and $\Delta \mathrm{GW}$ displayed statistically significant declines $(p<0.05)$, while the other hydrological variables displayed insignificant changes in their overall trends. $\triangle \mathrm{GW}$ showed significant decreased trend in CA at a rate of $41.18 \mathrm{~mm} / \mathrm{year}$, leading to a reduction in the overall GRACE-TWSC at a rate of $50.4 \mathrm{~mm} /$ year. Human activity is the main cause of the GW storage depletion.

(2) $\mathrm{P}$ is an important factor affecting important hydrological processes in CA. ET, GRACE-TWSC, and GLDASTWSC showed strong positive correlations with annualscale $\mathrm{P}$ anomalies. In addition, the influence of $\mathrm{P}$ on various variables in the hydrological process had a lag effect. The largest lag response of $\Delta \mathrm{GW}$ corresponded to a $\mathrm{P}$ lag of 2 to 3 months. The correlation between the lag of $\mathrm{P}$ and GRACE-TWSC was more obvious than that of GLDAS-TWSC. The correlation between GLDAS-TWSC and P-ET was highest with a lag time of 3 months. The correlation between hydrological variables was not found to be consistent among the time lags analyzed, as certain variables increased, while others did not increase at specific lag times.

(3) From 2003 to 2015 , NDVI showed a degradation trend in approximately $50 \%$ of CA. Changes in the NDVI exhibited heterogeneous changes in CA, with the main vegetation degradation areas concentrated around the Aral and Caspian Seas. The change in water in CA was closely related to the change in vegetation. The influence of hydrological variables on vegetation was not uniform. The impact of GRACE-TWSC and GLDAS-TWSC on the vegetation of the area was far 
greater than that of $\triangle \mathrm{GW}$ and P-ET. In the spring, $\mathrm{P}$ was the factor most important for vegetation growth, but during summer and autumn, this factor transitioned to SM.

Supplementary Information The online version contains supplementary material available at https://doi.org/10.1007/s00704-021-03730-w.

Author contribution Qing Peng: conceptualization, software, writing-original draft, formal analysis. Ranghui Wang: conceptualization, writing — review. Yelin Jiang: methodology, software, writingreview and editing. Cheng Li: formal analysis. Wenhui Guo: validation, writing—editing.

Funding This research was funded by the National Key Research and Development Program of China (Grant No. 2019YFC0507403), National Key Technologies R \& D Program of China (2012BAD16B0305), and National Natural Science Foundation of China (41801013).

Availability of data and material All data generated or analyzed during this study are included in this published article (and its supplementary information files).

Code availability The codes that support the findings of this study are available from the corresponding author.

\section{Declarations}

Ethics approval The authors declare that there is no human or animal participant in the study. Not applicable.

Consent to participate The authors declare that there is no human or animal participant in the study. Not applicable.

Consent for publication The authors give their consent to the publication of all details of the manuscript including texts, figures, and tables.

Conflict of interest The authors declare no competing interests.

Open Access This article is licensed under a Creative Commons Attribution 4.0 International License, which permits use, sharing, adaptation, distribution and reproduction in any medium or format, as long as you give appropriate credit to the original author(s) and the source, provide a link to the Creative Commons licence, and indicate if changes were made. The images or other third party material in this article are included in the article's Creative Commons licence, unless indicated otherwise in a credit line to the material. If material is not included in the article's Creative Commons licence and your intended use is not permitted by statutory regulation or exceeds the permitted use, you will need to obtain permission directly from the copyright holder. To view a copy of this licence, visit http://creativecommons.org/licenses/by/4.0/.

\section{References}

Andrew RL, Guan H, Batelaan O (2017) Large-scale vegetation responses to terrestrial moisture storage changes. Hydrol Earth Syst Sci 21(9):4469-4478. https://doi.org/10.5194/ hess-21-4469-2017
Bai J, Shi H, Yu Q, Xie Z, Li L, Luo G, Jin N, Li J (2019) Satelliteobserved vegetation stability in response to changes in climate and total water storage in Central Asia. Sci Total Environ 659:862-871. https://doi.org/10.1016/j.scitotenv.2018.12.418

Berghuijs WR, Woods RA, Hrachowitz M (2014) A precipitation shift from snow towards rain leads to a decrease in streamflow. Nat Clim Chang 4(7):583-586. https://doi.org/10.1038/nclim ate 2246

Bernauer T, Siegfried T (2012) Climate change and international water conflict in Central Asia. J Peace Res 49(1):227-239. https://doi.org/10.1177/0022343311425843

Brecht M, Miralles DG, Hans L, Robin VDS, De JRAM, Diego FP, Beck HE, Dorigo WA, Verhoest NEC (2016) GLEAM v3: satellite-based land evaporation and root-zone soil moisture. Geoscientific Model Development Discussions:1-36

Chen Y, Li W, Deng H, Fang G, Li Z (2016) Changes in Central Asia's water tower: past, present and future. Sci Rep 6:35458. https://doi.org/10.1038/srep35458

Chen YN, Li Z, Fang GH, Li WH (2018) Large hydrological processes changes in the transboundary rivers of Central Asia. J Geophys Res-Atmos 123(10):5059-5069. https://doi.org/10. 1029/2017jd028184

Chou C, Neelin JD, Chen C-A, Tu J-Y (2009) Evaluating the "richget-richer" mechanism in tropical precipitation change under global warming. J Clim 22(8):1982-2005. https://doi.org/10. 1175/2008jcli2471.1

Curreli A, Wallace H, Freeman C, Hollingham M, Stratford C, Johnson H, Jones L (2013) Eco-hydrological requirements of dune slack vegetation and the implications of climate change. Sci Total Environ 443:910-919. https://doi.org/10.1016/j.scitotenv. 2012.11.035

D’Odorico P, Bhattachan A, Davis KF, Ravi S, Runyan CW (2013) Global desertification: drivers and feedbacks. Adv Water Resour 51:326-344. https://doi.org/10.1016/j.advwatres.2012.01.013

de Beurs KM, Henebry GM, Owsley BC, Sokolik I (2015) Using multiple remote sensing perspectives to identify and attribute land surface dynamics in Central Asia 2001-2013. Remote Sens Environ 170:48-61. https://doi.org/10.1016/j.rse.2015.08.018

Deng H, Chen Y (2017) Influences of recent climate change and human activities on water storage variations in Central Asia. J Hydrol 544:46-57. https://doi.org/10.1016/j.jhydrol.2016.11.006

Farinotti D, Longuevergne L, Moholdt G, Duethmann D, Mölg T, Bolch T, Vorogushyn S, Güntner A (2015) Substantial glacier mass loss in the Tien Shan over the past 50 years. Nat Geosci 8(9):716-722. https://doi.org/10.1038/ngeo2513

Feng X, Fu B, Piao S, Wang S, Ciais P, Zeng Z, Lü Y, Zeng Y, Li Y, Jiang X, Wu B (2016) Revegetation in China's Loess Plateau is approaching sustainable water resource limits. Nat Clim Chang 6(11):1019-1022. https://doi.org/10.1038/nclimate3092

Gao H, Li H, Duan Z, Ren Z, Meng X, Pan X (2018) Modelling glacier variation and its impact on water resource in the Urumqi Glacier No. 1 in Central Asia. Sci Total Environ 644:1160-1170. https:// doi.org/10.1016/j.scitotenv.2018.07.004

Gerten D, Schaphoff S, Haberlandt U, Lucht W, Sitch S (2004) Terrestrial vegetation and water balance - hydrological evaluation of a dynamic global vegetation model. J Hydrol 286:249-270. https:// doi.org/10.1016/j.jhydrol.2003.09.029

Ghazanfari S, Pande S, Hashemy M, Sonneveld B (2013) Diagnosis of GLDAS LSM based aridity index and dryland identification. J Environ Manage 119:162-172. https://doi.org/10.1016/j.jenvm an.2013.01.040

Greve P, Orlowsky B, Mueller B, Sheffield J, Reichstein M, Seneviratne SI (2014) Global assessment of trends in wetting and drying over land. Nat Geosci 7(10):716-721. https://doi.org/10.1038/ngeo2 247 
Harris I, Jones P (2017) CRU TS4. 01: Climatic Research Unit (CRU) Time-series (TS) version 4.01 of high-resolution gridded data of month-by-month variation in climate (Jan. 1901-Dec. 2016). 25. https://doi.org/10.5285/58a8802721c94c66ae45c3baa4d814d0

Held IM, Soden BJ (2000) Water vapor feedback and global warming. Annu Rev Energy Env 25(1):441-475. https://doi.org/10.1146/ annurev.energy.25.1.441

Hu Z, Zhang C, Hu Q, Tian H (2014) Temperature changes in Central Asia from 1979 to 2011 based on multiple datasets*. J Clim 27(3):1143-1167. https://doi.org/10.1175/jcli-d-13-00064.1

Jiang L, Guli J, Bao A, Guo H, Ndayisaba F (2017) Vegetation dynamics and responses to climate change and human activities in Central Asia. Sci Total Environ 599-600:967-980. https://doi.org/10. 1016/j.scitotenv.2017.05.012

Jiao Y, Lei H, Yang D, Huang M, Liu D, Yuan X (2017) Impact of vegetation dynamics on hydrological processes in a semi-arid basin by using a land surface-hydrology coupled model. J Hydrol 551:116-131. https://doi.org/10.1016/j.jhydrol.2017.05.060

Li C, Zhang C, Luo G, Chen X, Maisupova B, Madaminov AA, Han Q, Djenbaev BM (2015a) Carbon stock and its responses to climate change in Central Asia. Glob Change Biol 21(5):1951-1967. https://doi.org/10.1111/gcb.12846

Li Z, Chen Y, Fang G, Li Y (2017) Multivariate assessment and attribution of droughts in Central Asia. Sci Rep 7(1):1316. https://doi. org/10.1038/s41598-017-01473-1

Li Z, Chen Y, Li W, Deng H, Fang G (2015b) Potential impacts of climate change on vegetation dynamics in Central Asia. J Geophys Res-Atmos 120(24):12345-12356. https://doi.org/10.1002/ $2015 \mathrm{jd} 023618$

Liu L, Zhang R, Zuo Z (2016) The Relationship between Soil Moisture and LAI in Different Types of Soil in Central Eastern China. J Hydrometeorol 17(11):2733-2742. https://doi.org/10.1175/ jhm-d-15-0240.1

Lohse KA, Brooks PD, McIntosh JC, Meixner T, Huxman TE (2009) Interactions between biogeochemistry and hydrologic systems. Annu Rev Environ Resour 34(1):65-96. https://doi.org/10.1146/ annurev.environ.33.031207.111141

Long D, Chen X, Scanlon BR, Wada Y, Hong Y, Singh VP, Chen Y, Wang C, Han Z, Yang W (2016) Have GRACE satellites overestimated groundwater depletion in the Northwest India Aquifer? Sci Rep 6:24398. https://doi.org/10.1038/srep24398

Martens B, Miralles DG, Lievens H, van der Schalie R, de Jeu RAM, Fernandez-Prieto D, Beck HE, Dorigo WA, Verhoest NEC (2017) GLEAM v3: satellite-based land evaporation and root-zone soil moisture. Geoscientific Model Development 10(5):1903-1925. https://doi.org/10.5194/gmd-10-1903-2017

Meng SS, Xie XH, Zhu BW, Wang YB (2020) The relative contribution of vegetation greening to the hydrological cycle in the Three-North region of China: a modelling analysis. J Hydrol 591:125689. https://doi.org/10.1016/j.jhydrol.2020.125689

Ndehedehe CE, Ferreira VG, Agutu NO (2019) Hydrological controls on surface vegetation dynamics over West and Central Africa. Ecol Indicators 103:494-508. https://doi.org/10.1016/j.ecolind. 2019.04.032

Panda DK, Wahr J (2016) Spatiotemporal evolution of water storage changes in India from the updated GRACE-derived gravity records. Water Resour Res 52(1):135-149. https://doi.org/10. 1002/2015wr017797

Qi H, Huang F, Zhai H (2019) Monitoring spatio-temporal changes of terrestrial ecosystem soil water use efficiency in Northeast China using time series remote sensing data. Sensors (Basel) 19 (6). https://doi.org/10.3390/s19061481

Qin Y, Yang D, Lei H, Xu K, Xu X (2015) Comparative analysis of drought based on precipitation and soil moisture indices in Haihe basin of North China during the period of 1960-2010. J Hydrol 526:55-67. https://doi.org/10.1016/j.jhydrol.2014.09.068

Ravi S, Breshears DD, Huxman TE, D'Odorico P (2010) Land degradation in drylands: interactions among hydrologic-aeolian erosion and vegetation dynamics. Geomorphology 116(3-4):236-245. https://doi.org/10.1016/j.geomorph.2009.11.023

Reyer CP, Leuzinger S, Rammig A, Wolf A, Bartholomeus RP, Bonfante A, de Lorenzi F, Dury M, Gloning P, Abou Jaoude R, Klein T, Kuster TM, Martins M, Niedrist G, Riccardi M, Wohlfahrt G, de Angelis P, de Dato G, Francois L, Menzel A, Pereira M (2013) A plant's perspective of extremes: terrestrial plant responses to changing climatic variability. Glob Chang Biol 19(1):75-89. https://doi.org/10.1111/gcb.12023

Rodell M, Chen J, Kato H, Famiglietti JS, Nigro J, Wilson CR (2006) Estimating groundwater storage changes in the Mississippi River basin (USA) using GRACE. Hydrogeol J 15(1):159-166. https:// doi.org/10.1007/s10040-006-0103-7

Rodell M, Houser PR, Jambor U, Gottschalck J, Mitchell K, Meng CJ, Arsenault K, Cosgrove B, Radakovich J, Bosilovich M, Entin JK, Walker JP, Lohmann D, Toll D (2004) The global land data assimilation system. Bull Am Meteor Soc 85(3):381-394. https:// doi.org/10.1175/bams-85-3-381

Save H, Bettadpur S, Tapley BD (2016) High-resolution CSR GRACE RL05 mascons. Journal of Geophysical Research: Solid Earth 121(10):7547-7569. https://doi.org/10.1002/2016jb013007

Shen C, Niu J, Phanikumar MS (2013) Evaluating controls on coupled hydrologic and vegetation dynamics in a humid continental climate watershed using a subsurface-land surface processes model. Water Resour Res 49(5):2552-2572. https://doi.org/10.1002/wrcr. 20189

Song C, Yuan L, Yang X, Fu B (2017) Ecological-hydrological processes in arid environment: Past, present and future. J Geogr Sci 27:1577-1594. https://doi.org/10.1007/s11442-017-1453-x

Suzuki R, Masuda K, G. Dye D, (2007) Interannual covariability between actual evapotranspiration and PAL and GIMMS NDVIs of northern Asia. Remote Sens Environ 106(3):387-398. https:// doi.org/10.1016/j.rse.2006.10.016

Syed TH, Famiglietti JS, Rodell M, Chen J, Wilson CR (2008) Analysis of terrestrial water storage changes from GRACE and GLDAS. Water Resources Research 44 (2). https://doi.org/10.1029/2006w r005779

Tan C, Guo B, Kuang H, Yang H, Ma M (2018) Lake area changes and their influence on factors in arid and semi-arid regions along the silk road. Remote Sens 10 (4). https://doi.org/10.3390/rs 10040595

Thomas A (2008) Development and properties of 0.25-degree gridded evapotranspiration data fields of China for hydrological studies. J Hydrol 358 (3-4):145-158. https://doi.org/10.1016/j.jhydrol. 2008.05.034

Thomas AC, Reager JT, Famiglietti JS, Rodell M (2014) A GRACEbased water storage deficit approach for hydrological drought characterization. Geophys Res Lett 41(5):1537-1545. https://doi. org/10.1002/2014gl059323

Wahren CHA, Walker MD, Bret-Harte MS (2005) Vegetation responses in Alaskan arctic tundra after 8 years of a summer warming and winter snow manipulation experiment. Glob Change Biol 11(4):537-552. https://doi.org/10.1111/j.1365-2486.2005.00927.x

Wang Y, Zhang Y, Chiew FHS, McVicar TR, Zhang L, Li H, Qin G (2017) Contrasting runoff trends between dry and wet parts of eastern Tibetan Plateau. Sci Rep 7(1):15458. https://doi.org/10. 1038/s41598-017-15678-x

Xie Y, Huang S, Liu S, Leng G, Peng J, Huang Q, Li P (2018) GRACEbased terrestrial water storage in Northwest China: changes and causes. Remote Sens 10 (7). https://doi.org/10.3390/rs10071163

Xu M, Kang S, Chen X, Wu H, Wang X, Su Z (2018a) Detection of hydrological variations and their impacts on vegetation from 
multiple satellite observations in the Three-River Source Region of the Tibetan Plateau. Sci Total Environ 639:1220-1232. https:// doi.org/10.1016/j.scitotenv.2018.05.226

Xu S, Yu Z, Yang C, Ji X, Zhang K (2018b) Trends in evapotranspiration and their responses to climate change and vegetation greening over the upper reaches of the Yellow River Basin. Agric for Meteorol 263:118-129. https://doi.org/10.1016/j.agrformet. 2018.08.010

Yang K, Ye B, Zhou D, Wu B, Foken T, Qin J, Zhou Z (2011) Response of hydrological cycle to recent climate changes in the Tibetan Plateau. Clim Change 109:517-534. https://doi.org/10.1007/ s10584-011-0099-4

Yang T, Wang C, Chen Y, Chen X, Yu Z (2015) Climate change and water storage variability over an arid endorheic region. J Hydrol 529:330-339. https://doi.org/10.1016/j.jhydrol.2015.07.051
Zhang G, Li Z, Wang W, Wang W (2014) Rapid decrease of observed mass balance in the Urumqi Glacier No. 1, Tianshan Mountains. Central Asia Quaternary International 349:135-141. https://doi. org/10.1016/j.quaint.2013.08.035

Zhang YW, Deng L, Yan WM, Shangguan ZP (2016) Interaction of soil water storage dynamics and long-term natural vegetation succession on the Loess Plateau, China. CATENA 137:52-60. https:// doi.org/10.1016/j.catena.2015.08.016

Publisher's note Springer Nature remains neutral with regard to jurisdictional claims in published maps and institutional affiliations. 